\title{
Engels's Theory of Social Murder and the Spectacle of Fascism: A Critical Enquiry into Digital Labour and its Alienation
}

\author{
Aishik Saha \\ Independent Researcher, Kolkata, India, aishikjadavpur1994@gmail.com
}

\begin{abstract}
In this paper, I shall attempt to respond to the charge that the digital labour theory, as developed by Christian Fuchs, doesn't faithfully stick to the Marxist schema of the Labour Theory of Value by arguing that Marx's critique of capitalism was based on the social and material cost of exploitation and the impact of capitalist exploitation of the working class. Engels's analysis of The Condition of The Working Class in England links the various forms of violence faced by the working class to the bourgeois rule that props their exploitation. I shall argue, within the framework of Critical Social Media Studies, that the rapid advance of fascist and authoritarian regimes represents a similar development of violence and dispossession, with digital capitalism being a major factor catalysing the rifts within societies. It shall be further argued that much like the exploitative nature of labour degrades social linkages and creates conditions of that exaggerates social contradictions, the "labour" performed by social media users degenerates social relations and promotes a hyper-violent spectacle that aids and abets fascist and authoritarian regimes.
\end{abstract}

Keywords: digital labour, society of the spectacle, fascism, filter bubbles, alienation

Acknowledgement: Criticisms and suggestions provided by Dr. Utsa Ray, Assistant Professor at Jadavpur University, Department of History, and Ayan Chandra, researcher at IITKharagpur, have been extremely helpful with writing this paper.

\section{Introduction}

This paper will attempt at a convergence of multiple trajectories of critical research in social media studies. Starting with an analysis of the concept of digital labour it will be argued that rethinking contemporary debates is required in the light of the developments in $\mathrm{Al}$ and machine learning over the past decades. We will then attempt to understand Engels's conception of alienation from a Marxist-Humanist perspective, and attempt to locate the alienation of digital labour within this framework. Next, we will look at recommender systems and the role of alienated digital labour in the development of its algorithms, and the development of filter bubbles that lead to echo chambers of right-wing opinion. Finally, our analysis of these echo-chambers and the role of social media brings us to the society of the spectacle as defined by Guy Debord, where social relations are distorted by the violence of the spectacle.

\section{A Critical Rethinking of Digital Labour}

The emergence of Critical Social Media Studies and the concept of digital labour have attracted its fair share of critiques. The main issue that these critiques share is the rather unorthodox categorisation of labour and subsequently its view of exploitation. In order to develop an understanding of the concept of digital labour, we must look at the definition of labour itself, especially in its relation to the overall Marxist 
framework within which the concept has been formulated. It is also important to look at the types of labour actually being engaged by users rather than simply pigeonholing them into pre-existing categories of labour.

The commodity has two distinct aspects, use-value and exchange-value, which are of a contradictory nature (Marx 1867; Marx 1865). The use-value of a commodity refers to the utility of the commodity, and can only be realised in either use or consumption (Marx 1867, 126). The exchange-value of a commodity, on the other hand, refers to the quantitative relation in which use-values of one kind can exchange for use-values of another. In a class society, exchange-value is itself created through the use of labour-power, which must then be reproduced. Marx $(1867,320)$ divides this labour-power into necessary labour, i.e. labour that creates all the necessary values for the reproduction of labour-power, and surplus-labour, i.e. labour that creates surplus-value over and above what is necessary for the reproduction of labour-power. This divides work-time into the categories of necessary labour-time and surplus labour-time with surplus valu' being created from the latter. Capitalists seek to maximise the production of surplus value, either by increasing the total work-time (which can be done by mainly extending the length of the workday) or decreasing the duration of the necessary labour-time, which is then taken up by surplus labour-time (which can mainly be done by introducing more productive technology).

The theoretical underpinnings of digital labour lie in rethinking the concepts of value and abstract labour as simultaneous expressions of political economy and socio-political class struggle (Fuchs 2014). Fuchs and Sevignani (2013) outline the the Hegel-Marxist triangle model of work, which is then employed to develop the concept of digital work, which defines communication itself as a form of work. This approach however negates the concept of immaterial labour involved in the production of the cultural content of a commodity (Hardt and Negri 2004; Lazzarato 1996). Fuchs $(2014,252)$ has argued that information work is material itself, and is intrinsically linked to the materiality of work and thus doesn't require a distinct categorical marker. Dallas Smythe (1977b) argues that the development of what he calls the consciousness industry represents an encroachment of the leisure time of workers through the use of advertisements. He develops the concept of the audience commodity, where the labour-power of workers is sold as a commodity through the medium of advertisements (Smythe 1977a; 1977b). The conditions under which this sale of labourpower takes place are distinct from the commonly known form of the exchange of value, as the working audience is both the subject and the object of this transaction. The audience performs the labour of learning about the particular brand, and is thus responsible for the creation of demand for that particular commodity within the domain of monopoly capitalism (Smythe 1977b). Thus, the process of reproduction of labour-power in itself is congealed into the audience labour performed by the workers/audience. In order to understand digital labour, the concept of the audience commodity is modified into the concept of the Internet prosumer commodity (Fuchs 2014, 93-94). Digital labour follows the trajectory set by the concept of audience labour, with users being both producers of content as well as its main consumers, while at the same time generating a surplus-value of Internet prosumer commodities, which can then be sold to advertisers (Fuchs 2013).

In the book Culture and Economy in the Age of Social Media, Fuchs (2015) outlines the major debates surrounding digital labour, so for our purposes we will briefly take a look at the critiques of the application of Marx's theory of value to digital labour. James Reveley (2013) has argued for the abandonment of the concept of digital labour in favour of a Marxist pursuit of social media's influence on labour-power. 
The argument he makes is that the overall framework of the Labour Theory of Value that Marx has espoused is not strictly adhered to, especially the relation between necessary labour and surplus labour. He also negates Smythe's concept of the audience commodity on the basis of the same objection. The same rejection of the Marxist theorisation of value forms the basis of the criticism by Arvidsson and Colleoni (2012). Rather than the sale of a prosumer commodity, "any discussion of value needs to take into account the central role finance plays in the appropriation and distribution of value" (Arvidsson and Colleoni 2012, 136). Kaan Kangal's critique argues that user information is already a commodity before it enters the Internet and thus users cannot be said to produce value, and argues that Fuchs' "exploitation thesis dislocates the source of profit made by media companies from selling the advertisement rights to the value production of Internet users" (Kangal 2016, 7). Bolaño and Vieira (2015) on argue that the concept of the audience commodity remains a valid analytical tool, but say that the idea of users performing labour needs to be criticised. They argue: "What is sold by Google, by the way, is not the users themselves [...] because the advertiser does not buy any individual users or even their singular information. Advertisers buy only an amount of data about a target audience based on categories, as we have outlined" (Bolaño and Vieira 2015). A similar approach is shared by Robinson, who argues that advertising on the Web 2.0 actually helps "realize value produced elsewhere" rather than being the source of surplus-value itself (Robinson 2014, 50).

The confusion regarding the role and labour of Internet users is primarily due to the diversity of the types of activity and the ways in which Web 2.0 functions. Christoph Raetzsch (2016) raises this issue by pointing out to the diverse ways in which different websites like Facebook, Twitter, Instagram, as well as search engines like Google or online encyclopaedias like Wikipedia work. The inability to perform a differential diagnosis of the rate of profit is the main reason that many of the critics of the theory of digital labour refuse to analyse it within a Marxist framework (Reveley 2013; Arvidsson and Colleoni 2012). In treating data as a pre-existing use-value, as emphasised by the metaphors of oil and coal, the interaction between users and social media platforms as experience is overlooked (World Economic Forum 2012; Raetzsch 2016). However, Interactive Machine Learning (IML) has introduced us to a different conceptualisation of digital labour. Defined as "the science of getting computers to realize a task without being explicitly programmed", Machine Learning has essentially automated the task of developing algorithms for mining through data (Rocca 2019). Not only do the users provide data, they are, in this model, actually performing the labour of training algorithms. This point is stressed by Amershi et al. $(2014,106)$ who point out that in contrast to conventional machine learning, "model updates in IML are more rapid (the model gets updated immediately in response to user input), focused (only a particular aspect of the model is updated), and incremental (the magnitude of the update is small; the model does not change drastically with a single update). This allows users to interactively examine the impact of their actions and adapt subsequent inputs to obtain desired behaviors. As a result of these rapid interaction cycles, even users with little or no machine-learning expertise can steer machine-learning behaviors through low-cost trial and error or focused experimentation with inputs and outputs". The participation of networked communities like those of social media can boost the incremental nature of updates to a more dynamic one. Within the IML model, the users definitely do perform labour, which leads to updates of algorithms and an overall advancement of the recommender systems. The advances in machine learning through user inputs means that users are also participat- 
ing in the process of alienation. Dead labour is in this manner being used to appropriate labour-power, which represents the classic Marxist confrontation between labour and capital. Understanding this alienation is thus crucial to understanding the way in which digital labour is transforming contemporary capitalism.

\section{Engels and Marxist Humanism}

Our conception of exploitation cannot however be satisfied with a mechanistic understanding of exploitation, but rather has to look at the effects of exploitation and alienation on the working class itself. Engels's analysis in The Condition of the Working Class in England (1845b) provides an understanding of the capitalist exploitation of the industrial working class in $19^{\text {th }}$ century England. Engels laid the ground for the critique of the political economy of capitalism. In this section, we shall interrogate the role of digital labour and its forms of alienation, and its impact on the socio-historical process, especially by analysing the Marxist Humanism of Friedrich Engels.

The question of alienation features prominently here and we must deal with it briefly before proceeding. Gajo Petrović $(1963,421)$ summarises Marx's views:

Marx begins with the alienation of the results of man's labor, alienation of objects produced by man. The realization of labor is its objectification, and this objectification is for the laborer at the same time the loss of object, alienation. To the product of his labor the worker is related as to an alien object. Products of his hands constitute a separate world of objects which is alien to him, which dominates him, and which enslaves him.

Dead labour, which is capital, can only survive by extracting living labour, and thus the relationship between capital and labour is perennially antagonistic. Marx (1844) points out in the Economic and Philosophic Manuscripts of 1844 that there are four stages of alienation that occur within a class society:

- The alienation of a person's own labour, and subsequently the alienation of the products of their labour.

- The alienation of the process of production, which ensures that productive activity results in the subjugation of the worker rather than their freedom.

- The alienation of the worker, who is a creative being, from their creative ability. By depriving a worker of their creative ability, Marx opines that the process alienates the worker from their humanity itself.

- The alienation of humans from their own species being. The relationship between humans is distorted by the prism of class society, i.e. the contemporary capitalist society.

The final point leads us to an understanding of commodity fetishism where relationships between commodities become a determinant for social relationships between humans. The alienated labour therefore goes on to dominate the worker, who has performed the labour to produce it. Finally the increasing accumulation of capital enables the displacement of the worker into the ranks of the unemployed reserve army of labour. Thus, the greater amount of labour workers perform, the more they contribute to their own alienation and oppression.

Engels has, over the past century, been dogged by the tag of being a vulgar materialist, in one form or the other, and has been posed against Marx's more Hegelian tendencies. Before we proceed to establish Engels's humanist credentials, we must 
seek to understand what Marxism's contribution to humanist philosophy has been and to what extent Marxism itself is a humanist philosophy. Donald Clark Hodges $(1965,191)$ has argued that one of Marx's critical contribution to humanism was "its addition of a material, bodily, passionate and sensuous content to traditional humanism and the elevation of this content to the status of liberal activity" and "its development of the social and humanitarian elements of traditional humanism". Raya Dunayevskaya $(1965,63)$ has in fact argued that not only is the view that Marx abandoned his early humanist philosophy false, but conversely humanism "gives Marx's magnum opus its force and direction". She points out that Marx's critique of commodity fetishism and alienation is integral to Marxism rather than simply a stepping stone to the critique of capital. A similar line of argument is forwarded by John Roche (2005) in his critique of Louis Althusser, demonstrating that Marx's critique of human alienation and human liberation draws upon Feuerbach's critique of religious alienation. He also opines that Marx champions the proletariat as he views struggling workers as agents of human liberation. In its unification of the world of sensuous and spiritual experiences Marxism seeks human liberation in the liberation from the material conditions that make such exploitation possible.

If the proletariat is viewed as the agent of human liberation, it is Engels who must be credited with recognising its crucial role, which then became a definitive aspect of both his and Marx's works. Ann Dennehy (1996) writes that the earliest works of Engels lacks a proper theoretical framework through which he could analyse his perspectives on the impoverishments that he saw. This synergy between Marx's and Engels's own inputs helps in placing the "blank face and figure of Marx's abstract proletarian" into "a real house and real factory" (Wilson 1940, 146). Engels (1845b) establishes through his Dickensian description of the living and working condition of the working class the true nature of exploitation. In his studies of the early communist colonies the contrast with the wretched conditions of the industrial working class is rather clearly presented (Engels 1845b). Engels's condemnation of the capitalist system is quite clear:

When one individual inflicts bodily injury upon another such injury that death results, we call the deed manslaughter; when the assailant knew in advance that the injury would be fatal, we call his deed murder. But when society places hundreds of proletarians in such a position that they inevitably meet a too early and an unnatural death, one which is quite as much a death by violence as that by the sword or bullet [...] (Engels 1845b, 393-394)

Engels's recognition of this social murder caused by hunger, starvation and disease, or even the precarious conditions of living that make one prone to various fatal accidents is clearly aimed at the hypocrisy of bourgeois humanism and thus seeking to extend the boundaries of humanist thought to include the industrial proletariat. These social murders are not limited to industrial towns or capitalist countries but also extend into the domains of the colonies. The multiplicity of plagues and famines in the colonies can only be explained as products of capitalist alienation. The role of alienation figures heavily as the main instrument in ensuring inequality, which in turn acts as a motivator for workers to continue participating in the system. Richard Peet (1975) points out that this hierarchical inequality needs to be recreated, which is largely achieved through a geographical uneven distribution of resources. Engels too notes that the graded inequality marks the difference between the English and Irish 
workers in England, with English workers being more disposed towards skilled work, while the Irish workers were filling the ranks of workers with less technical expertise.

Kun Wu and Qiong Nan (2020) point to the expansion of the scope of dialectics by Engels, including the critique of idealist dialectics, which led to the emergence of materialist dialectics. In Dialectics of Nature (1883), as E. San Juan Jr. (1995) argues, Engels (1883) sees motion as an inherent attribute of matter that can help us to comprehend all processes occurring in the universe including thought. This is viewed as an erasure of subjectivity in Engels's works, which denies any possibility of revolutionary action (Lukács 1971). However San Juan Jr. (1995, 412) identifies the revolutionary potential of Engels's ideas of aesthetics, which like "religion [...] is one of the fruits of the alienating division of labor". Thus, while religion is understood to be a result of the alienation of humans from their species being, aesthetics can be seen as a reflection of the alienated creative being. In Description of Recently Founded Communist Colonies, Engels (1845a) argues that once all tasks are within the community, i.e. no longer being performed for capitalist profit but rather the overall use of all community members, their menial nature itself becomes meaningless.

Digital labour confronts the prosumer by extremist online communities that are able to mobilise and inflict violence, which I propose should be included within the phenomenon of social murder. Engels's recognition of human creativity's revolutionary potential and the sources of its alienation, as well as the reproduction of this alienation, helps us place it within the framework of the humanist conception of liberation. The categorisation of social murder as a distinct feature of capitalist domination and a necessary aspect of the capitalist alienation of labour marks a major contribution to the understanding of alienation itself.

\section{The Alienation and Cyber-Balkanisation of Social Media}

It should by now be clear that digital capitalism has created its own forms of alienation, which in turn supports the development of hyper-nationalist/fascist ideologies in their wake. I shall borrow Van Alstyne and Brynjolfsson's (2005) concept of CyberBalkans in order to understand the growth of fascism in the digital era. It is necessary to explore the legitimisation of fringe discourses through social media, and the development of a distorted consciousness and the forces which help the process. This will help us understand why the internet, instead of creating a space for free exchange of views and knowledge has rather helped as the expansion of forces of bigotry.

Understanding the role played by recommender systems (RS) and the business models of social media sites is crucial to explaining the social divergence that lies at the root of the alienation caused by digital capitalism. In general RSs suggests content, denoted as items, to users based on a host of factors (Ricci, Rokach and Shapira 2011). The main task of a RS is identifying the interests of a user, whom we have identified in the paper as a prosumer, and then providing meaningful recommendations. With the rise of social media, many have sought to utilise these social linkages in developing and evaluating newer recommendation models, one such being the trust-enhanced recommendation techniques (Victor, De Cock and Cornelis 2011). Social networking sites like Facebook have provided a vast pool of data for recommender systems (Shapira, Rokach and Freilikhman 2013). In fact, the value of a recommendation is often determined by the strength of the interpersonal ties between the users (Oechslein and Hess 2014). Inputs from the user regarding their tasks through their likes, shares, and public engagement helps the recommender algorithm identify the user's interests. The platform profits from being able to target users with highly specific advertisements and thus relies on the 
accuracy of its recommendations (Curran, Graham and Temple 2011). The utilisation of social advertising through boosted collaborative filtering demonstrates that Facebook is incentivised to combine different filtering models in order to precisely target audiences (Fan and Chang 2010).

Multiple studies have shown that online communities tend to coalesce into homogeneous groups with similar views. Eli Pariser (2011) emphasises that the Internet, based on the user's previous searches and interests, can present very different pictures of the world, which he argues results in a filter bubble that makes it increasingly difficult for users to encounter dissenting opinions. Jacobson, Myung and Johnson $(2015,13)$ have pointed out that on the Facebook wall of partisan news sites "audiences have a limited number of sources they prefer to reference when discussing the news". The growth of polarised communities or echo-chambers is also highlighted by Del Vicario et al. (2016), demonstrating that the effect of polarisation increases in both scientific and conspiracy theory-based communities. The more a user engages with the community, the more polarised their opinion tends to be. In the case of Twitter, it has been demonstrated that users prefer to engage with other users of similar political views and share from sources that affirm their positions (Himelboim, McCreery and Smith 2013). Studies of the debates surrounding Brexit as well as vaccination debates have demonstrated how the polarisation process takes place on social media (Schmidt et al. 2018; Vicarioa et al. 2017). A contrary view is presented by Möller et al. (2018) and Haim, Graefe and Brosius (2018). They point out that personalised and non-personalised news usually tend to have the same diversity. However they do not seem to consider that recommendations don't only come from the recommender systems but also other users who are a part of the network of the user. The bias is thus structured into the recommender system's logic rather than one that creeps in through usage. This phenomenon of cyber-balkanisation was predicted by Van Alstyne and Brynjolfsson (2005), though they seem to have underestimated the role that increasing pressures of commercialisation on social media sites and social recommender systems may have played. One may argue that social media sites are incentivised to expose users to a limited set of content mainly based on a user's interaction with other users and their own preferences, since it is useful for advertisers to target audiences most receptive to their messages. Recommenders are thus calibrated to increasingly serve this function.

This phenomenon of cyber-balkanisation has been exemplified by the mainstreaming of extremist politics of the right over the past decade. Tania Bucher (2012) points out that APIs can articulate politics, which O'Callagan et al. (2015) point out how YouTube's recommender algorithms can articulate right wing extremist politics. The model of platform capitalism, argues Tanner Mirrlees (2019), is what has allowed the alt-right to gain the kind of currency, which would otherwise have been outside of its reach leading to the platformisation of fascism. By repeatedly exposing users to a limited but trusted source of content, far-right politics is converted into an idea being performed on a platform, which legitimises its existence in the marketplace of ideas. While television, radio and other mass media have allowed politics to be performed, social media has allowed for performances to be politicised.

Siva Vaidhyanathan (2018) highlights that social media, while purportedly supporting the spread of democracy and freedom of speech across the world, has ironically given a major platform to political and social forces that subvert such objectives. Specifically focusing on Facebook, Vaidhyanathan $(2018,8)$ points out: 
Through its destructive influence on other media firms, industries, and institutions, Facebook undermines their ability to support healthy public deliberation as well. Facebook distorts the very sources of news and information on which a democratic republic relies.

Not only does Facebook change the way we see and share news, its business model has ensured that most advertising campaigns have shifted their focus to a social media centric model, which in turn has weaned away advertisement revenue from media houses. Trevor Garrison Smith (2017) on the other hand argues that the failure of political theorists to theorise politics in the digital age has resulted in a rejection of politics from both the left and the right. Fuchs $(2018,262)$ focuses on the neoliberal framework that has given rise to the authoritarian capitalism, pointing out that neoliberalism "is a huge machine of calculation and accumulation that tries to turn everything into a commodity". Since everything has been commoditised, it goes without saying that politics itself has been commoditised, lending itself to a far greater extent to the principles of advertisement and marketing than simple political rhetoric. Facebook and other social networking sites primarily rely on algorithmic surveillance of user metadata in order to provide targeted advertisements (Doyle 2014). Much like commercial establishments, algorithmic surveillance allows political groups to target specific demographics based on recommender algorithms. The distortion thus takes place at two ends, with politics being framed increasingly to cater to digital demographics, and recipients of such politics also imagining themselves as parts of certain in-groups based on choice or identity rather than a class.

The alienation of digital labour, as with other forms of alienation, results in the alienation of the prosumer from their species-being, as we saw previously. The commodification of human creativity through social media lies at the root of this alienation. Digital labour alienated from the prosumer confronts them as an alien force by distorting the politics and society within the conditions of neoliberal capitalism. The role played by recommender systems and the creation of the filter bubble are crucial aspects of this distortion that represent a major role in the alienation of humans from their own species being, i.e. social alienation. Under these circumstances the prosumer is converted into a market demographic, with the intersection or contradiction between the two users determining their mutual interactions.

\section{Spectacular Alienation}

The notions of the spectacle and violence emerge as the key features of digital capitalism so far, and their inter-linkages must be explored to understand the process of alienation of digital labour. Guy Debord (1992) argues that the spectacle is created when the dominant mode of production invades the fabric of our social lives, where being itself becomes synonymous with having. Brad Evans and Henry A. Giroux (2015) point out that the spectacle of violence substitutes human empowerment. While we saw how alienated digital labour created the conditions for a spectacle in conditions of digital capitalism, how the spectacle creates conditions for the alienation of the prosumer class in particular and the overall working class in general remains obscured.

Debord $(1992,10)$ points out the fundamentally spectaclist nature of our modern society, underlining the power of the spectacle to subject human beings to itself is precisely due to the fact they have already been subjugated by the dominant mode of production, i.e. neoliberal capitalism. He further elaborates that given the alienating nature of the mode of production, life is identified with non-working time, i.e. leisure 
time. Here Marx's (1844) assessment of estranged labour confronting the worker as an alien force proves to be useful. Estranged labour is converted into the spectacle and performs two crucial tasks for the capitalist mode of production. On one hand, by imposing itself upon the leisure-time of the worker, it hinders the creative-ability of the worker (creative-being) by presenting celebrity-hood as the goal of social labour, while on the other hand, it falsifies social life on the basis of identities created out of trivialities, thus alienating the workers from their species-being.

The term infotainment though somewhat appropriate doesn't seem to grasp the cocktail of fear and hate that is channelised through social media, and is perhaps better exemplified as disinfotainment. Douglas Kellner (2003) points out to the multiple instances of the spectacle propagated through mass media like the OJ Simpson trial, conspiracy theories regarding alien invasions or bio-weapons, with even the presidential elections being converted into spectacles. The fact that the interplay between media and activism does play a crucial role in negotiating the visibility of dissent in the public space was noted by Bruce D'Arcus (2006), who described it as spectacles of dissent. Mohamed Nanabhay and Roxane Farmanfarmaian (2011, 574) point out that in the case of Egypt in the initial stages of the uprising against Hosni Mubarak, "citizens [were not only] able to produce their own footage but to distribute it through social networks, thus bypassing mainstream media as the traditional gatekeeper of news". In fact the role of social media throughout the Arab Spring has been widely remarked upon, as has its role in the Occupy Wall Street and other protests inspired by it. Paul Mihailidis and Samantha Viotty (2017) explored the participation of netizens in the spectacular US presidential elections of 2016, which demonstrated the fragmentation of social media discourse into closed-off echochambers and allowed for the proliferation of post-truth discourse. Hannah Arendt (1994) points out that rather than the ideologically convinced follower, the ideal subject of totalitarian rule is someone who has lost the ability to distinguish between truth and falsehood. Since all politics is reduced to a spectacle, this notion of truth and falsehood can easily be reduced to two contesting spectacles vying for dominance. Here the demand for social justice and racial equality is a spectacle to be counterpoising the demand for law and order. Similarly the narrative of environmental degradation, which is causing suffering in communities across the world is also dismissed as another spectacle, which is then confronted with the spectacle of a communist plot to dismantle capitalism in the United States. These spectacles aren't geographically or temporally restricted and find multiple manifestations in multiple conditions. The disinfotainment machine continues to manufacture these binaries, with politics and political struggle being replaced by competing spectacles.

Engels (1845c), as we previously saw, outlines the conditions in which the social murder of the working class takes place. In modern digital society, the politics of disposability creates new conditions of social murder. Henry A. Giroux (2010) refers to this as zombie politics where increasingly neoliberal policies results in the dispossession of millions of people, and are then categorised as human waste. David Harvey (2005) identifies this process of cutting down of public welfare measures while increasing the deregulation of private industry as accumulation by dispossession. This creates an increasing section of the population who are perennially exposed to the vagaries of the political economy, whom Guy Standing (2011) identifies as the precariat. Social murder in the twenty-first century takes a spectacular form, enacted on the screens of our smartphones and televisions, amplified by newsroom debates. 
The walking hyper-dead even oppose providing the extension of unemployment benefits to millions of Americans who are out of work, food, and hope. They spectacularize hatred and trade in lies and misinformation. They make populist appeals to the people while legitimating the power of the rich. They appeal to common sense as a way of devaluing a culture of questioning and critical exchange. Unrelenting in their role as archetypes of the hyper-dead, they are misanthropes trading in fear, hatred, and hyper-nationalism (Giroux 2011, 3).

In pitching human society against itself, neoliberal society no longer feels the need to justify its violence. Karen Laurie (2002) rightly identifies that the role of the news anchor has increasingly started to resemble that of a game show host, rather than a voice of reason. While the disinfotainment industry falsifies, spectacularises, and misrepresents information, the task of the anchor-host is to present both fact and fiction as equally valid. In this topsy-turvy world, the demand for free healthcare is the same as forcing doctors and nurses to work against their will. The demand for lowering of the cost of education and cancellation of burdensome education loans are the same as theft from those who have managed to pay off their loans. The demand for a living wage is a communist plot to destroy the economy. The demand for greater police accountability is encouragement to crime. Exposing war-crimes committed by American forces in Iraq or exposing the widespread surveillance of citizens is treason. The deaths caused by the lack of healthcare, police brutality, hate-crimes or imperialist wars can definitely be defined as social murders as Engels had defined the term.

Stuart Hall (1979) explores the contradictions that lead to the destruction of social democracy and allows for the emergence of authoritarian populism, leading to a new neoliberal consensus. A somewhat similar process has followed the 2007-2008 global financial crisis allowing for the emergence of a radical right focused on an antiimmigration and white nationalist rhetoric, which rejected international cosmopolitanism and the social security measures that supposedly draw the underserving immigrants to the developed economies in the West (Mirrlees 2019). Hall $(1979,14)$ points out that the general trends do not warrant overlooking the specific historical circumstances. We have seen earlier, certain studies have sought to critique the idea of the filter bubble (Haim, Graefe and Brosius 2018). However, the filter bubble exists not simply as a general phenomenon, but as a historical one in a neoliberalspectaclist society, where even exposure to opposing views can serve the purpose of further polarisation (Bail et al. 2018). The de-contextualisation of the politics behind the spectacle serves the purpose of polarisation rather than providing a holistic context to contradictions (Lyford and Payne 2005). Since, as Debord $(1992,1)$ points out, the spectacle is "a social relation between people that is mediated by images", it can be inferred that the role played by social media, presenting de-contextualised images from around the world, can only further increase fragmented views of reality. Here social media doesn't simply play the role of an amplifier of existing contradictions, but is rather an integral element of our contemporary neoliberal society. Social networking sites, in the process of prioritising their advertisement-based revenue models, ensure that recommender systems lead to filter bubbles, where fact diverges from its context and becomes a spectacle. This leads to an increase of human vulnerability to authoritarian populist manipulations, which we see happening at present. The process of de-contextualisation is in fact a powerful force that can delegitimise any narrative. Poverty without the context of the insidious but perpetual violence that gives rise to and maintains it, is simply laziness on the part of the poor to work their way out of poverty. Subsidised healthcare, food, education or other necessities can 
be constructed as free hand-outs, once we de-contextualise the very crucial task of social stability that they provide. Protests against police brutality, as we have seen recently, can be easily equated with savagery and looting, when taken out of the context of the centuries of violence against racial minorities. Slogans directed against America will seem a real threat unless seen from the perspective of decades of US involvement in imperialist wars around the world.

The alienation of the prosumer class is thus both manifested and manufactured through the spectacle. The disinfotainment industry, in its creation of multiple competing spectacles, essentially projects truth as a marketable commodity, to be malleable to the demands of the market. The blurring of the boundary between truth and falsehood creates the ideal conditions for totalitarian rule as Hannah Arendt points out. The de-contextualisation of facts lies at the root of the spectacle that mediates social relations through images. Under such conditions, violence is normalised and justified as necessary against illusory threats that are conjured by the spectacle. The grassroots mobilisation towards a totalitarian agenda enforced by violence against the most vulnerable communities mimics fascism adequately enough to be categorised into the same broad category. This social murder committed under the conditions of digital capitalism, through a withdrawal of necessary social security and increasingly violent instruments of legal coercion, is a crucial instrument in the arsenal of neoliberal capitalism in order to ensure the continued obedience on the part of the working class.

\section{Conclusion}

Our enquiries into the role played by digital labour in the process of IML, have demonstrated the process of alienation of digital labour. Machine learning algorithms represent dead labour, which can only sustain and reproduce itself by the living labour provided in the form of digital labour. The alienation of digital labour in the conditions of contemporary neoliberal capitalism leads to the creation of filter bubbles that correspond to the alienation of the worker (whom we have identified in our context as the prosumer) from their species being. The alienation from the species being is also manifested through the spectacle when the dominant mode of production completely subjugates society at large. Recommender systems have played a crucial role in the subjugation of social media to financialisation, which has been the key to the creation of filter bubbles. Finally we have discussed the growth of fascism as a product of the spectacle in society and on social media, which we have identified as social murder under the conditions of digital capitalism.

Engels's identification of social murder as an instrument of violence employed in the control of the working class becomes increasingly relevant. The most common form of social murder remains the active denial of necessities for existence like healthcare, protection against environmental calamities or degradation of health through pollutants, as even Engels had noted. This violence however is accompanied by physical and social violence.

In this country, social war is under full headway, every one stands for himself, and fights for himself against all comers, and whether or not he shall injure all the others who are his declared foes, depends upon a cynical calculation as to what is most advantageous for himself. It no longer occurs to anyone to come to a peaceful understanding with his fellow-man; all differences are settled by threats, violence, or in a law-court. In short, everyone sees in his neighbour an enemy to be got out of the way, or, at best, a tool to be used for his own ad- 
vantage. And this war grows from year to year, as the criminal tables show, more violent, passionate, irreconcilable" (Engels 1845c, 427).

The conditions of social murder thus include both "passive" and "active" violence against the most vulnerable sections of the society, and forms the bedrock of fascist violence. While Engels had anticipated that this antagonism would result in the confrontation between the Bourgeois and Proletariat, the reality of "Bonapartism" contradicted his own estimation.

While we should however avoid a simplistic equivalence between Bonapartism, as Engels described it, and our contemporary fascist movements, Bonapartism has been identified by a number of commentators as a proto-fascist movementsand was used by the Comintern as a prototype to model its analysis of fascism upon. Engels analysed the conditions of Bonapartism in the following manner:

Bonapartism is the necessary form of state in a country where the working class, at a high level of its development in the towns but numerically inferior to the small peasants in rural areas, has been defeated in a great revolutionary struggle by the capitalist class, the petty bourgeoisie and the army (Engels $1865,72)$.

Neoliberal capitalism played a major role in the defeat of the working class in our times. We have also recognised the intimate role of neoliberalism in developing digital capitalism and the subsequent use of the spectacle to dominate and control the workers. Engels attributes the rise of Bonapartism to a similar need for dominance and control over the working class. A clear and remarkable similarity emerges between the objectives and the tasks of Bonapartism and the spectaclist variety of fascism that emerges under conditions of digital capitalism. This spectaclist fascism prolongs the "social war of all against all" (Engels 1845b, 248) and continues with its historic task of perpetuating capitalist exploitation by disrupting the possibility of any extended working class solidarity, and intensifying the conditions that make social murder possible in a neoliberal society. Our analysis of digital labour has demonstrated that appropriation of prosumer labour plays a crucial role in this process.

Plainly stated, the digital labour performed by prosumers is converted into the spectaclist form of fascism and made into an instrument to control their social being. The fascist form both creates the condition of social murder and social violence through coercive apparatus of the state, ensuring the passive acceptance of the dominant mode of production and its legitimising ideology on the part of the working classes. This places us firmly within a Marxist terrain of analysis of digital labour, and demonstrates that digital labour is a distinct form of labour that can be recognised within a Marxist framework.

\section{References}

Amershi, Saleema, Maya Cakmak, William Bradley Knox, and Todd Kulesza. 2014. Power to the People: The Role of Humans in Interactive Machine Learning. Al Magazine 35 (4): 105-120.

Arendt, Hannah. 1994. The Origins of Totalitarianism. San Diego: Harcourt Brace \& Company.

Arvidsson, Adam and Elanor Colleoni. 2012. Value in Informational Capitalism and on the Internet. The Information Society 28 (3): 135-150. 
Bail, Christopher A., Lisa P. Argyle, Taylor W. Brown, John P. Bumpus, Haohan Chen, M. B. Fallin Hunzaker, Jaemin Lee, Marcus Mann, Friedolin Merhout, and Alexander Volfovsky. 2018. Exposure to Opposing Views on Social Media Can Increase Political Polarization. PNAS 115 (37): 9216-9221.

Bolaño, César R. S., and Eloy S. Vieira. 2015. The Political Economy of the Internet: Social Networking Sites and a Reply to Fuchs. Television \& New Media 16 (1): 52-61.

Bucher, Taina. 2012. Want to Be on the Top? Algorithmic Power and the Threat of Invisibility on Facebook. New Media \& Society 14 (7): 1164-1180.

Curran, Kevin, Sarah Graham, and Christopher Temple. 2011. Advertising on Facebook. International Journal of E-Business Development 26 (1): 26-33.

D'Arcus, Bruce. 2006. Boundaries of Dissent: Protest and State Power in the Media Age. New York: Routledge.

Debord, Guy. 1992. Society of the Spectacle. London: Rebel Press.

Del Vicario, Michela, Gianna Vivaldo, Alessandro Bessi, Fabiana Zollo, Antonio Scala, Guido Caldarelli, and Walter Quattrociocchi. 2016. Echo Chambers: Emotional Contagion and Group Polarization on Facebook. Scientic Reports 6: 37825, 1-12.

Dennehy, Anne. 1996. The Condition of the Working Class in England: 150 Years On. In Engels Today: A Centenary Appreciation, edited by Christopher J. Arthur, 95-128. New York: St. Martin's Press.

Doyle, Kim. 2014. Facebook, Whatsapp and the Commodification of Affective Labour. Communication, Politics \& Culture 48 (1): 51-65.

Dunayevskaya, Raya. 1965. Marx's Humanism Today. In Socialist Humanism: An International Symposium, edited by Erich Fromm, 63-76. New York: Doubleday \& Company.

Engels, Friedrich. 1883. Dialectics of Nature. In Marx \& Engels Collected Works (MECW) Volume 25, 313-590. London: Lawrence \& Wishart.

Engels, Friedrich. 1865. The Prussian Military Question and the German Workers' Party. In Marx \& Engels Collected Works (MECW) Volume 20, 37-79. London: Lawrence \& Wishart.

Engels, Friedrich. 1845a. Description of Recently Founded Communist Colonies Still in Existence. In Marx \& Engels Collected Works (MECW) Volume 4, 214-228. London: Lawrence \& Wishart.

Engels, Friedrich. 1845b. Speeches in Elberfeld. In Marx \& Engels Collected Works (MECW) Volume 4, 243-264. London: Lawrence \& Wishart.

Engels, Friedrich. 1845c. The Condition of the Working Class in England. In Marx \& Engels Collected Works (MECW) Volume 4, 295-583. London: Lawrence \& Wishart.

Evans, Brad, and Henry A. Giroux. 2015. Disposable Futures: The Seduction of Violence in the Age of Spectacle. San Francisco: City Lights Books.

Fan, Teng-Kai and Chia-Hui Chang. 2010. Learning to Predict Ad Clicks Based on Boosted Collaborative Filtering. 2010 IEEE Second International Conference on Social Computing, 209-216.

Fuchs, Christian. 2018. Digital Demagogue: Authoritarian Capitalism in the Age of Trump and Twitter. London: Pluto Press.

Fuchs, Christian. 2015. Culture and Economy in the Age of Social Media. New York: Rouledge.

Fuchs, Christian. 2014. Digital Labour and Karl Marx. New York: Routledge.

Fuchs, Christian. 2013. Digital Prosumption Labour on Social Media in the Context of the Capitalist Regime of Time. Time \& Society 23 (1): 1-27.

Fuchs, Christian and Sebastian Sevignani. 2013. What Is Digital Labour? What Is Digital Work? What's Their Difference? And Why Do These Questions Matter for Understanding Social Media? tripleC: Communication, Capitalism \& Critique 11 (2): 237-293.

Giroux, Henry A. 2011. Zombie Politics and Culture in the Age of Casino Capitalism. New York: Peter Lang. 
Giroux, Henry A. 2010. Zombie Politics and Other Late Modern Monstrosities in the Age of Disposability. Policy Futures in Education 8 (1): 1-7.

Haim, Mario, Andreas Graefe, and Hans-Bernd Brosius. 2018. Burst of the Filter Bubble? Digital Journalism 6 (3): 330-343.

Hall, Stuart. 1979. The Great Moving Right Show. Marxism Today. January: 14-20.

Hardt, Michael, and Antonio Negri. 2004. Multitude: War and Democracy in the Age of Empire. New York: The Penguin Press.

Harvey, David. 2005. A Brief History of Neoliberalism. New York: Oxford University Press.

Himelboim, Itai, Stephen McCreery and Marc Smith. 2013. Birds of a Feather Tweet Together: Integrating Network and Content Analyses to Examine Cross-ldeology Exposure on Twitter. Journal of Computer-Mediated Communication 18 (2): 40-60.

Hodges, Donald Clark. 1965. Marx's Contribution to Humanism. Science \& Society 29 (2): 173-191.

Jacobson, Susan, Eunyoung Myung, and Steven L. Johnson. 2015. Open Media or Echo Chamber: The Use of Links in Audience Discussions on the Facebook Pages of Partisan News Organisations. Information, Communication \& Society 19 (7): 1-17.

Kangal, Kaan. 2016. The Karl Marx Problem in Contemporary New Media Economy: A Critique of Christian Fuchs' Account. Television \& New Media 17 (5) 1-13.

Kellner, Douglas. 2003. Media Spectacle. New York: Routledge.

Laurie, Karen. 2002. News Anchor Or Games Show Host? Alternet, June 07. Accessed September 18, 2020. https://www.alternet.org/2002/06/news anchor or games show host/146965/

Lazzarato, Maurizio. 1996. Immaterial Labor. In Radical Thought in Italy: A Potential Politics, edited by Michael Hardt and Paolo Virno, 133-50. Minneapolis: University of Minnesota Press.

Lukács, Georg. 1971. History and Class Consciousness: Studies in Marxist Dialectics. Cambridge, MA: The MIT Press.

Lyford, Amy and Carol Payne. 2005. Photojournalism, Mass Media and the Politics of Spectacle. Visual Resources 21 (2): 119-129.

Marx, Karl. 1867. Capital. Volume I. London: Penguin.

Marx, Karl. 1865. Value, Price and Profit. In Marx \& Engels Collected Work (MECW) Volume 20, 101-149. London: Lawrence \& Wishart.

Marx, Karl. 1844. Economic and Philosophic Manuscripts of 1844. In Marx \& Engels Collected Works (MECW) Volume 3, 229-348. London: Lawrence \& Wishart.

Mihailidis, Paul and Samantha Viotty. 2017. Spreadable Spectacle in Digital Culture: Civic Expression, Fake News, and the Role of Media Literacies in "Post-Fact" Society. American Behavioral Scientist 61 (4): 1-14.

Mirrlees, Tanner. 2019. The Alt-Right's Platformization of Fascism and a New Left's Digital United Front. Democratic Communiqué 28 (2): 28-46.

Möller, Judith, Damian Trilling, Natali Helberger, and Bram van Es. 2018. Do Not Blame It on the Algorithm: An Empirical Assessment of Multiple Recommender Systems and their Impact on Content Diversity. Information, Communication \& Society 21 (7): 959-977.

Nanabhay, Mohammed, and Roxanne Farmanfarmaian. 2011. From Spectacle to Spectacular: How Physical Space, Social Media and Mainstream Broadcast Amplified the Public Sphere in Egypt's "Revolution". The Journal of North African Studies 16 (4): 573-603.

O'Callaghan, Derek, Derek Greene, Maura Conway, Joe Carthy, and Pádraig Cunningham. 2015. Down the (White) Rabbit Hole: The Extreme Right and Online Recommender Systems. Social Science Computer Review 33 (4): 459-478.

Oechslein, Oliver and Thomas Hess. 2014. The Value of a Recommendation: The Role of Social Ties in Social Recommender Systems. 47th Hawaii International Conference on System Sciences: 1864-1873.

Pariser, Eli. 2011. The Filter Bubble: What the Internet is Hiding from You. New York: The Penguin Press. 
Peet, Richard. 1975. Inequality and Poverty: A Marxist-Geographic Theory. Annals of the Association of American Geographers 65 (4): 564-571.

Petrović, Gajo. 1963. Marx's Theory of Alienation. Philosophy and Phenomenological Research 23 (3): 419-426.

Raetzsch, Christoph. 2016. Is Data the New Coal? Four Issues With Christian Fuchs on Social Media. Networking Knowledge 9 (5): 1-21.

Reveley, James. 2013. The Exploitative Web: Misuses of Marx in Critical Social Media Studies. Science \& Society 77 (4): 512-535.

Ricci, Francesco, Lior Rokach, and Bracha Shapira. 2011. Introduction to Recommender Systems Handbook. In Recommender Systems Handbook, edited by Francesco Ricci, Lior Rokach, Bracha Shapira and Paul B. Kantor, 1-35. New York: Springer.

Robinson, Bruce. 2014. With a Different Marx: Value and the Contradictions of Web 2.0 Capitalism. The Information Society 31 (1): 44-51.

Rocca, Joseph. 2019. A Simple Introduction to Machine Learning. Towards Data Science. December 23. Accessed August 22, 2020. https://towardsdatascience.com/introductionto-machine-learning-f41aabc55264

Roche, John. 2005. Marx and Humanism. Rethinking Marxism 17 (3): 335-348.

San Juan Jr., E. San Juan. 1995. The Revolutionary Aesthetics of Frederick Engels. Nature, Society, and Thought 8 (4) 405-432.

Schmidt, Ana Lucía, Fabiana Zollo, Antonio Scala, Cornelia Betsch, and Walter Quattrociocchi. 2018. Polarization of the Vaccination Debate on Facebook. Vaccine 36 (25): 36063612.

Shapira, Bracha, Lior Rokach, and Shirley Freilikhman. 2013. Facebook Single and Cross Domain Data for Recommendation Systems. User Modeling and User-Adapted Interaction 23 (2-3): 211-247.

Smith, Trevor Garrison. 2017. Politicizing Digital Space: Theory, the Internet, and Renewing Democracy. London: University of Westminster Press.

Smythe, Dallas. 1977a. Communications: Blindspot of Western Marxism. Canadian Journal of Political and Social Theory 1 (3): 1-27.

Smythe, Dallas. 1977b. Critique of the Consciousness Industry. Journal of Communication 27 (1): 198-232.

Standing, Guy. 2011. The Precariat: The New Dangerous Class. London: Bloomsbury Academic.

Vaidhyanathan, Siva. 2018. Anti-Social Media: How Facebook Disconnects Us and Undermines Democracy. New York: Oxford University Press.

Van Alstyne, Marshall and Erik Brynjolfsson. 2005. Global Village or Cyber-Balkans? Modeling and Measuring the Integration of Electronic Communities. Management Science 51 (6): 851-868.

Vicarioa, Michela Del, Fabiana Zolloa, Guido Caldarellia, Antonio Scalab, and Walter Quattrociocchi. 2017. Mapping Social Dynamics on Facebook: The Brexit Debate. Social Networks 50: 6-16.

Victor, Patricia, Martine De Cock, and Chris Cornelis. 2011. Trust and Recommendations. In Recommender Systems Handbook, edited by Francesco Ricci, Lior Rokach, Bracha Shapira and Paul B. Kantor, 645-675. New York: Springer.

Wilson, Edmund. 1940. To the Finland Station. New York: Doubleday \& Company.

World Economic Forum. 2012. Personal Data: The Emergence of a New Asset Class. WEF Report 1-40.

Wu, Kun and Qiong Nan. 2020. The Contemporary Value of Engels' Dialectics. International Journal of Systems Science and Applied Mathematics 5 (2): 12-19. 


\section{About the Author}

Aishik Saha is an independent researcher. He has obtained his M.A. in History from Jadavpur University in India. His research interests include Critical Theory, Fascisms, Comparative Politics, Global South and Colonialism. 